\title{
A Discordance Weighting Approach Estimating Occupational and Income Returns to Education
}

\author{
Matthew A. Andersson \\ Department of Sociology, Baylor University, Waco, TX, USA
}

\begin{abstract}
Schooling differences between identical twins are often utilized as a natural experiment to estimate returns to education. Despite longstanding doubts about the truly random nature of within-twin-pair schooling discordance, such discordance has not yet been understood comprehensively, in terms of diverse betweenand within-family peer, academic, familial, social, and health exposures. Here, a predictive analysis using national U.S. midlife twin data shows that within-pair schooling differences are endogenous to a variety of childhood exposures. Using discordance propensities, returns to education under a true natural experiment are simulated. Results for midlife occupation and income reveal differences in estimated returns to education that are statistically insignificant, suggesting that twin-based estimates of causal effects are robust. Moreover, identical and fraternal twins show similar levels of discordance endogeneity and similar responses to propensity weighting, suggesting that the identical twins may not provide demonstrably better leverage in the causal identification of educational returns.
\end{abstract}

Keywords: returns to education, natural experiment, twins, childhood, occupation (SEI), income

Education receives attention from social scientists because it is relevant to understanding core processes of social inequality and is linked to a range of important differences in adult outcomes (Heckman \& Krueger, 2003; Hout, 2012). Social scientists often use identical (monozygotic, MZ) twins to estimate the causal effect of education on life outcomes such as earnings, health, social integration, fertility, or behaviors such as volunteering or criminal offending. These applications-common in economics, sociology, and personality and developmental psychology-rest on observed differences within pairs of MZ twins in education (the causal treatment) and in outcomes. At an elementary level, any observed differences between identical twins in their education are understood as reflecting unshared environmental factors within twin pairs or differences between families. Beyond this, however, treatment differences between identical twins remain poorly understood and have received little attention. Increased clarity about the nature, extent, and predictors of such within-pair variation is critical, because within-pair variation is often assumed to proxy random assignment (Boardman \& Fletcher, 2015; McGue et al., 2010).

To date, few studies have sought to understand the extent to which within-pair differences in education truly resemble a randomized controlled trial, similar to how, for example, institutional changes in the length of mandatory schooling or the beginning date of the school year serve as natural experiments (e.g., Angrist \& Krueger, 1991). In this study, a comprehensive approach to within-pair educational discordance is implemented. Specifically, I analyze the extent to which differences between twins resemble a quasi-experiment, by using observed sources of endogeneity both within and between families to reweight causal estimates of returns to education. In a national U.S. sample of identical twins at midlife, I analyze educational discordance in terms of diverse childhood, peer, academic, familial, social, and health exposures within and across twin pairs; I then use the predicted discordance probabilities to reweight the data, and I compare weighted and unweighted estimates of returns to education, namely midlife income and occupation, to determine the degree to which observed determinants of educational differences among identical twins might bias causal estimates. In a replication of the discordance weighting procedure, I focus on same-sex fraternal (dizygotic) twins. Fraternal twins provide a meaningful benchmark for evaluating the extent to which identical twins provide additional leverage in estimating the causal effects of education (Bound \& Solon, 1999).

RECEIVED 20 January 2018; ACCEPTED 22 March 2018. First published online 23 April 2018.

ADDRESS FOR CORRESPONDENCE: Matthew A. Andersson, Department of Sociology, Baylor University, One Bear Place \#97326, Waco, TX 76798-7326, USA. E-mail: matthew_ andersson@baylor.edu 


\section{Approaches to Obtaining Causal Estimates of Returns to Education}

Education is one of the most widely researched sources of social inequality. Despite sustained inquiry, estimating a causal effect of education remains difficult (Amin et al., 2015; Conti \& Heckman, 2010). Much methodological interest has focused on estimating an average treatment effect of education, or what might obtain under a trial or experiment in which educational differences occurred randomly among participants. Attempting to simulate these ideal conditions, interest in counterfactual analyses, and in quasiexperimental data, has increased dramatically.

Counterfactual analyses using a national sample of unrelated individuals (e.g., Panel Study of Income Dynamics (PSID), National Longitudinal Survey of Youth (NLSY)) typically begin by matching unrelated individuals on a rich set of pre-education observables, such as cognitive and noncognitive skills and family resources, and then they simulate an experiment under the strong assumption of ignorability of any unobserved endowments (e.g., Brand \& Xie, 2010). Similarly, a schooling function is specified as a complex vector of early skills or variables, and a heterogeneous treatment effect of schooling is assessed across levels of this function, barring unobserved confounding (e.g., Conti \& Heckman, 2010). As demonstrated elsewhere, the conclusions of such analyses can be quite sensitive to unobserved baseline differences (Breen et al., 2015).

Given the unrealistic goal of measuring all relevant educational inputs, interest in quasi-experimental data is increasing. Policy experiments tend to fall short of providing good estimates of average treatment effects of education, however, because they exploit variation in narrow ranges of attainment and so provide insight into causal effects at certain points in the educational distribution, rather than across the entire distribution (Angrist \& Krueger, 1991; Pischke \& von Wachter, 2008).

By contrast, differences between twins may offer better purchase on an average treatment effect of education. Because twins differ on their education across much of the educational distribution, and because national twin samples demographically resemble national samples of unrelated individuals, some scholars have argued that twins provide an important avenue for estimating an average treatment effect of education (Card, 1999). Conditioning on the twin pair, as accomplished through focusing on differences within twin pairs, controls a host of unobserved genetic and familial influences that vary across pairs, even relative to non-twin sibling designs (Bound \& Solon, 1999). Indeed, co-twins have been regarded as 'credible counterfactuals' and may provide an important avenue for estimating the causal effects of educational treatments (Kohler et al., 2011; McGue et al., 2010). Nevertheless, a longstanding discussion in applied econometrics questions the exogeneity or randomness of within-pair schooling differences (e.g., Behrman \& Rosenzweig, 1999; Bound \& Solon, 1999; Griliches, 1979).

\section{Within-Twin-Pair Schooling Differences: To What} Extent are They Exogenous?

Anecdotal evidence suggests that within-pair differences are likely to be patterned by differing childhood and familylevel exposures (Bound \& Solon, 1999, p. 1975; Lundborg, 2013), but empirical treatments of the precise nature or extent of within-pair schooling remain limited. Studies have used birth weight to instrument within-pair schooling differences, but this is considered a flawed identification technique because differences in birth weight are likely associated with later differences in Intelligence Quotient (IQ) and thus adult outcomes such as wages (Bound \& Solon, 1999; Sandewall et al., 2014). Early differences in noncognitive skills or health seem to have limited ability to predict within-pair educational discordance (Isacsson 1999; Lundborg et al. 2011). It has recently been suggested that within-pair variation on educational attainment is related to parental socio-economic status, though patterns remain unclear (Amin et al., 2015; Lundborg, 2013).

Two recent studies examined whether educational differences in sense of control or depressive symptoms among young-adult twins can be explained by within-pair differences relevant to predicting educational attainment, such as differences among twins in their educational expectations, cognitive ability, personality, or health behaviors (McFarland \& Wagner, 2015; McFarland et al., 2016). Using within-pair multiple regressions implicating diverse domains of social, health, and personality functioning, these studies importantly advance previous efforts, while compellingly suggesting that within-pair confounding is partially responsible for observed associations between higher education and mental wellbeing. However, these findings do not allow between-pair (between-family) factors to influence discordance probability, an assumption probably not warranted given earlier research. In addition, lifecourse temporal ordering is lacking for some of the withinpair confounders examined, leaving direction of causality ambiguous, and confounder endogeneity to mental wellbeing also makes the viability of the educational estimates uncertain to some extent. Finally, ramifications for later-life outcomes, after educational attainments are complete, remain unclear.

The present study considers midlife occupation and income, which represent processes transpiring after education is complete and which are likely to be influenced directly by education through labor market allocation processes or educational sorting. Classic literature on educational attainment among unrelated individuals, which is fundamental in sociology and economics, has shown that childhood and adolescent peer networks, classroom sorting and teacher exposure, demographic and parental differences, early social and emotional skills, and early substance use, for example, all predict final educational attainment (e.g., Conti \& Heckman, 2010; Crosnoe \& Riegle-Crumb, 2007; Entwisle et al., 2005; McLeod \& Fettes, 
2007; Sewell et al., 1969). Twins may differ on any number of these well-established determinants of educational attainment. In that case, within-pair educational variation would not be exogenous and this may threaten the validity of causal estimates unless steps are taken to deal with it.

\section{Objectives of the Current Study}

Relative to prior quasi-experimental twinning studies, the present work attempts several contributions to estimating returns to education. First, it more extensively specifies within- and between-family pathways for within-pair educational discordance, providing greater insight into the childhood and early-life origins of attainment differences between twins. In taking a comprehensive multivariate approach, this study generally moves beyond the existing approaches to educational discordance, which tend to be anecdotal, bivariate, or domain-specific. Second, I use a propensity score weighting approach to discover the nature and extent of bias in estimates of midlife occupational and financial returns to education.

Third, I replicate the analyses on a sample of same-sex fraternal (DZ) twins. Much of the appeal of MZ twins rests on their genetic matching relative to fraternal twins. While the added value of MZ twins for causal analysis may seem self-evident, the extent to which MZ twins, compared to DZ twins, reduce the endogeneity of within-pair schooling has not been investigated for occupation and income using a rich set of life-course covariates predictive of discordance within and between families.

\section{Materials and Methods}

\section{Sample}

National data on educational outcomes and childhood exposures among twins come from the 1995-1996 National Survey of Midlife Development in the United States (MIDUS) funded by the John D. and Catherine T. MacArthur Foundation (available on the ICPSR website: http://www.icpsr.umich.edu). Twins were aged 25-74 years at the time of the first (Random Digit Dial (RDD)) interview, which took place in 1995-1996. About 60\% of initially chosen twin respondents agreed to the phone interview and, of these, $92 \%$ agreed to complete additional questionnaires. Data are available for 1,764 fraternal and identical twin respondents. After restricting the twin sample to families reporting two twins (due to the requirements of the within-pair differencing procedure), 348 pairs of identical twins remained. For the replication using same-sex fraternal twins, 304 pairs were available. ${ }^{1}$

Of these available pairs, analysis is restricted to those showing less than 3 years of discordance in schooling (310 MZ pairs and $242 \mathrm{DZ}$ ) for year-based estimates of returns to education, and to those showing less than three levels of discordance in schooling (343 MZ pairs and 294 DZ) for level-based estimates of educational returns. This sampling restriction allows for the estimation of a variety of discordance models so as to examine robustness to the specification of discordance. Other discordance models using all twin pairs without any upper discordance restriction produced comparable findings for discordance dynamics and treatment-weighted returns to education (available on request). For estimating midlife returns to education, these sample sizes are made slightly lower by missing data on occupational socio-economic status (about 3\% of the MZ sample, $2 \%$ of the DZ) and household income (9\% MZ, $10 \% \mathrm{DZ})$.

\section{Measures}

Outcomes: Returns to education (occupational SEI and household income). Occupational prestige is measured using the Duncan socio-economic index (SEI) score; if the respondent is not currently working, previous SEI is used. Household income is censored at $\$ 300,000$ in MIDUS. Because within-pair differences in household income follow an approximately normal distribution, raw household income is used. I do not report results for individual respondent's income here due to higher rates of non-response, though they yielded similar findings (available on request).

Education. MIDUS asks respondents to report their final educational attainment in terms of credential points (e.g., completion of high school, General Equivalency Diploma (GED), Associate's degree, Bachelor's, Master's, or doctorate) or partial progress toward credentials (e.g., some high school, 1 or 2 years of college). For main analyses involving years of schooling, I recoded this measure to years of education (4-20 years). For supplementary analysis using level of schooling, I instead reduced the variable to five key categories (less than high school, high school, some college, college, and graduate).

Discordance predictor variables: Within- and betweentwin-pair exposures. To predict within-pair education discordance I draw on established, basic determinants of educational attainment (e.g., Astone \& McLanahan, 1991; Conti \& Hansman, 2013; McLeod \& Fettes, 2007; Sewell et al., 1969). Given that these determinants are important to understanding differences in attainment between unrelated individuals, they should extend to understanding differences between related individuals who differ in childhood conditions. To the extent that twins differ in this respect, they are expected to differ on educational attainment as well. Indeed, many of these variables have already been used to explain differences in attainment among siblings and twins. ${ }^{2}$

Childhood peer, academic, familial and social environment (within twin pairs). While identical twins share many aspects of their childhood environment, they also have unshared exposures. I measure these unshared 
exposures using a set of variables referring to peer, academic, familial, and social exposures. To begin, twins were asked whether they shared the same playmates and same classrooms as their co-twin growing up (never, sometimes, most of the time, or always). Most twins selected 'always' or 'most of the time' for these two items, so I contrast these two categories with all other categories.

Familial exposures include time spent in joint living spaces and similarity of exposure to parenting. Most identical twins reporting sharing a bedroom for between 16 and 18 years during childhood, so I contrast these twins with those who did not. Also, I consider whether twins lived together for fewer than 18 years $(1=$ yes, $0=$ no). Finally, I consider differential exposure to parental discipline, in terms of strictness, consistency, harshness, and restrictiveness (four items; queried separately by parent, alphas $=0.77$ and 0.83 ). For each twin, a parental discipline score is generated by averaging across maternal and paternal discipline or taking the available value when one is missing.

In terms of social exposures, twins assessed whether distant relatives or acquaintances had difficulty telling them apart (never, sometimes, most of the time, and always). Again, due to a highly skewed response distribution, I focus here on 'always' or 'most of the time'. Others' difficulty differentiating between co-twins measures the extent to which twins present themselves differently to others and also the extent to which others perceive (or are motivated to perceive) the twins as different. In other words, this is likely to tap differences in appearance, interpersonal behavior, and/or non-cognitive skills, all of which carry plausible links to eventual differences in schooling.

In addition to environmental exposures, biological and health differences are also core considerations for understanding adult socio-economic attainment. Twins were asked to report on their exact weight at birth (pounds and ounces). About $50 \%$ of identical twins reported their birth weight; analyses described later examined robustness to missing data on birth weight (see McFarland et al., 2016, for a similar strategy). Twins also rated whether they had similar weight during most of their childhood (within 10 pounds of each other, yes or no). Differences in childhood weight reflect differences in non-cognitive, cognitive, and peer factors once conditioned on socio-economic differences (von Hippel \& Lynch, 2014). Twins also reported the ages at which they began smoking or drinking regularly; I focus on any between-twin differences in childhood or adolescent initiation by coding initiation at or before 18 years $(1=$ yes, $0=$ no). Finally, twins reported on their overall mental health at age 16 years (poor, fair, good, very good, or excellent). I focus on whether the twins differed by more than one unit in reported adolescent mental health $(1=$ yes, $0=$ no).

Demographic and parental variables (family level, between twin pairs). At the twin-pair level, I consider sex, age, and race. I also consider parental socio-economic status, in terms of parental education and parental SEI. I focus on the maximum attained level of education across both parents (less than high school, high school, some college, college, and graduate), and I focus on the general level of maximum parental SEI (high $=$ top 50\% SEI in MIDUS sample, moderate $=25$ th to 50 th percentile). A categorical SEI approach recognizes the fact that incremental, unitwise gains in SEI generally are not relevant to understanding broad patterns in twin educational discordance, but that qualitative differences in SEI (e.g., professional or managerial vs. clerical or manual) are relevant. To capture severe economic deficiencies, I also consider whether the twins' family ever received welfare during childhood. Finally, I included a measure of parental health when the respondent's age was 16 years (excellent, very good, good, fair, or poor).

To capture geographic variation in college completion rates, I indicate whether twin families grew up in a predominantly rural or small-town setting. Since moves during childhood tend to uproot peer relationships and schooling arrangements and may induce within-pair differences in schooling processes (Pribesh \& Downey, 1999; South \& Haynie, 2004), I also considered how many times the family moved to a new neighborhood or town during childhood, up to a maximum of four times.

\section{Analytic Procedure: Discordance Treatment Propensity Equation, Calculating Treatment Weights, and Treatment-Weighted Estimation of Returns to Education}

Treatment equation: Specification and estimation. The classic approach using identical twins to estimate the causal effect of a treatment, $T$, begins with a linear equation specifying the outcome, $Y$, as a function of genetic, $G$, family, $F$, and idiosyncratic, $U$, components:

$$
Y_{i j}=\theta_{1} G_{i}+\theta_{2} F_{i}+\gamma T_{i j}+U_{i j}
$$

Here, $i$ indexes families (twin pairs) and $j$ indexes individuals. Because MZ twins are genetically identical and share the same family environment, I can take the difference among each pair of twins and write

$$
\begin{aligned}
& \Delta Y_{i}=\gamma \Delta T_{i}+\Delta U_{i} \equiv \\
& \Delta Y_{i}=\gamma D_{i}+V_{i} .
\end{aligned}
$$

Under the assumption that $D$ is independent of $V$ (i.e., $D \perp V), \gamma$ is the causal effect of $T$ on $Y$. A weaker assumption is that $D$ is conditionally independent of $V$, given observed predictors of $D$, that is,

$$
D_{i}=X_{i}^{\prime} \beta+\varepsilon_{i}
$$

and $\varepsilon \perp V$. In this case, by conditioning on the $X$ 's, I can recover the causal effect of $T$ on $Y$.

The analysis starts with equation (3). Given the small number of values of $D$ in data, I write the probability that $D$ takes the specific value $k$ (where $k$, educational discordance, 
may be 1 or 2 years or levels of education), as a linear function of predictors:

$$
\operatorname{pr}(D=k)=\sum_{a}^{A} \beta_{a k} Z_{i}+\sum_{b}^{B} \beta_{b k} X_{i}+\varepsilon_{i} .
$$

Here, the unit of observation is the twin pair. $Z$ is withintwin pair differences in variables that can differ between twins in the same pair, while $X$ denotes variables that differ between twin pairs-that is, shared characteristics of a twin pair.

I estimate equation (4), the discordance treatment equations, as linear probability models using full-information maximum likelihood (FIML) with a robust covariance matrix in Stata 13. FIML uses all available information for each observation and builds the likelihood function casewise rather than imputing data, thus retaining all valid cases. It is preferred to multiple imputation for missing data for reasons detailed by Allison (2002). FIML is advantageous here because it allows one to recover substantial amounts of data missing at random due to the design of the MIDUS survey and to birth-weight non-response in particular (affecting around $50 \%$ of twin pairs). Discordance models estimated using list-wise deletion and a more basic set of covariates so as to preserve sample size (e.g., excluding birth weight) produced similar results for overall model fit. Results using a non-linear link function (e.g., logit) also produced the same substantive results.

Calculating inverse probability of treatment (IPT) weights for twin pairs. Using the discordance treatment equation parameter estimates, I calculate the estimated probability (propensity score) of each educational discrepancy for each twin pair and I use these to reweight the data, with the weights inversely proportional to the particular discrepancy (educational treatment) observed (Austin, 2011; Malone et al., 2014, p. 411). The weights are stabilized by multiplying them by the proportion of pairs that received each treatment. Relative to unweighted or raw twin data, the weighted data more closely simulate a natural experiment on education, where educational treatment is orthogonal to participant characteristics.

Estimating returns to education using twin-pair fixed effects. In the final stage of analysis, I obtain fixed-effects (within-pair) estimates of midlife occupational and financial returns to education. Numerous methods are available for the regression-based analysis of twin data (Carlin et al., 2005). When one desires simply to eliminate unobserved genetic and shared environmental heterogeneity, withinpair-differencing using identical twins is the most straightforward estimation strategy (Griliches 1979). Accordingly, I estimate equation 2 (above) by OLS through the origin with robust standard errors. Using both the unweighted and weighted data I obtain estimates of $\gamma$, the effect of education on the outcome, $Y$.

\section{Results}

\section{Sample Overview: MZ and Same-Sex DZ Twins}

Appendix A (Table A.1) provides detailed descriptive statistics for the identical (MZ) and same-sex fraternal (DZ) twin samples. All educational variables and outcomes are summarized, as are all variables for the educational discordance equations. $\mathrm{MZ}$ and $\mathrm{DZ}$ twins are middle-aged at the time of the MIDUS survey (about 45 years old) and show average education levels of some college (about 14 years of completed schooling), average occupational SEI of 38 points, and average household income of about $\$ 72,000-\$ 75,500$.

As expected, MZ twins are more similar on education, occupation, and income than DZ twins. However, MZ twins show slightly higher absolute levels of education and income than DZ twins. On the educational discordance variables, the twin samples come from similar social class backgrounds (as measured by parent education and welfare receipt during childhood), though MZ twins show slightly higher parental socio-economic resources. MZ twin pairs are more likely to be male than same-sex DZ pairs, more likely to share childhood bedrooms, playmates, and classrooms, to have similar childhood weight, and to have relatives and acquaintances who had difficulty telling them apart during childhood. Also, MZ twins are less likely to differ on early substance use and mental health than DZ twins.

\section{Predicting Within-Twin-Pair Differences in Education}

Table 1 summarizes model fit parameters from regressions predicting educational discordance within twin pairs based on the discordance equation variables. These regressions are specified as two binary linear probability models. In the first model, the outcome variable is a discordance of 1 year of schooling between twins, relative to no discordance or 2 years of discordance. In the second model, the outcome is 2 years of discordance, relative to none or 1 year. Parameter estimates for these discordance equations are given in Appendix B (Tables B.1 and B.2).

For MZ and DZ twins alike, the 1-year model does not demonstrate significant fit overall, so I do not interpret individual coefficients. However, the 2-year model predicts discordance significantly better than the sample expectation; MZ fit: Wald $\chi^{2}(30)=63.08, p<.001$, BentlerRaykov $R^{2}=0.145$; DZ fit: Wald $\chi^{2}(30)=57.99, p<.01$, Bentler-Raykov $R^{2}=0.163$. In the MZ 2-year discordance model (Table B.1), white racial status and higher levels of parental education (relative to non-white racial status and parental education less than high school) are significantly and positively linked to a discordance of 2 years in education (relative to no discordance or 1 year of discordance). These coefficients are quite large, corresponding to predicted probability increases of greater than 0.1. Meanwhile, 
TABLE 1

Summary of Educational Discordance Model Fit, MZ and DZ Twins

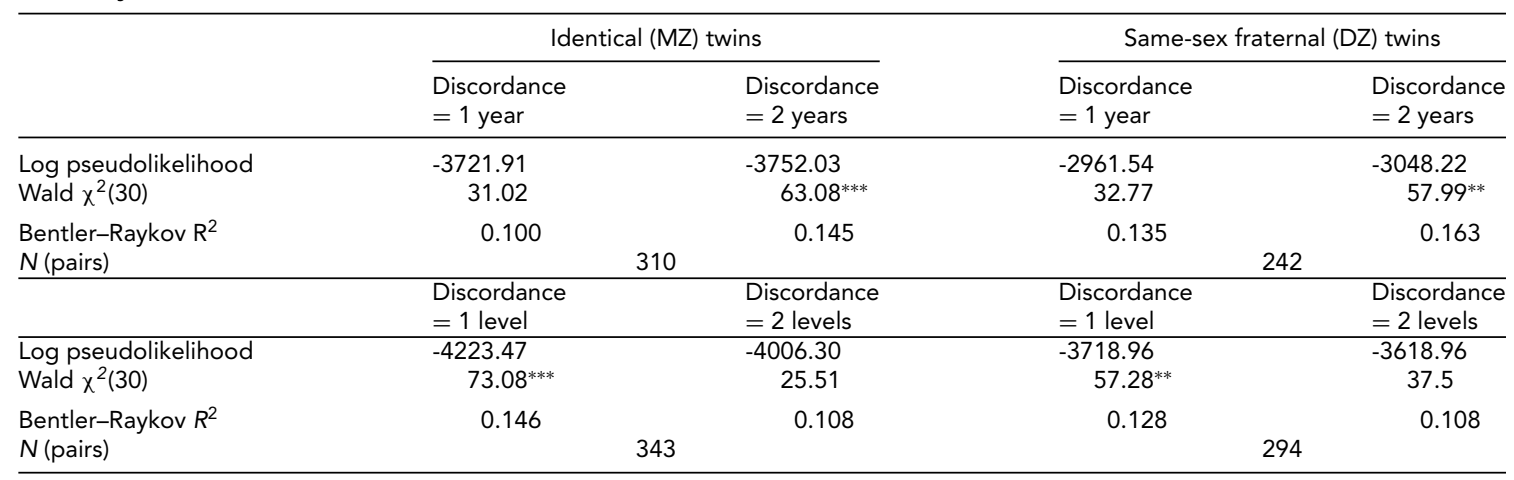

Note: Model fit summaries based on FIML estimation of binary educational discordance models. For Discordance $=1$ models, reference outcome is 0 or 2 years or levels of educational discordance. For Discordance $=2$ models, reference outcome is 0 or 1 year or levels of discordance (Levels = some high school or less, high school graduate, some college, college graduate, and graduate). ** $p<.01 ;{ }^{* * *} p<.001$ (two-tailed).

sharing the same bedroom throughout childhood is positively linked to discordance as well, as is confusion among relatives in telling the twins apart; whereas sharing the same school classrooms, confusion among acquaintances, and differences in early drinking are negatively linked to discordance probability. In the DZ 2-year discordance model (Table B.2), high parental SEI is positively linked to 2 years of discordance, whereas increases in parental health, shared childhood playmates, and differences in birth weight are negatively linked to 2 years of educational discordance.

When within-twin-pair educational discordance is modeled instead in terms of levels of education, a one-level discordance model shows significant fit for the $\mathrm{MZ}$ and $\mathrm{DZ}$ twin samples alike; MZ fit: Wald $\chi^{2}(30)=73.08, p<.001$, Bentler-Raykov $R^{2}=0.146$; DZ fit: Wald $\chi^{2}(30)=57.28$, $p<.01$, Bentler-Raykov $\left.R^{2}=0.128\right)$, whereas the twolevel discordance equation does not demonstrate fit superior to the sample expectation. The fit obtained here generally aligns with the year-based discordance model results, in which one level of educational discordance typically corresponds to about 2 or 3 years of educational discordance.

Tables B. 3 and B. 4 report the parameter estimates for the level-based discordance models. In the MZ one-level discordance model (Table B.3), white racial status is positively linked to one level of discordance relative to two levels or no discordance, whereas moderate parental SEI, confusion among acquaintances, and differences in parental discipline growing up are negatively linked. In the $\mathrm{DZ}$ one-level discordance model (Table B.4), younger ages (relative to omitted age group: $40-44$ years) are linked to a higher probability of discordance, as is moving for more times during childhood relative to no residential moves.

The discordance parameter estimates then were used to generate treatment weights for year-based and level-based estimation of the midlife returns to education. Appendix C (Table C.1) shows the distributions of the stabilized treatment weights.

\section{Estimates of Midlife Returns to Education (With and Without Treatment Weighting)}

Table 2 shows estimates of the occupational (SEI) returns to education (top panel) and the income returns (bottom panel). I report three sets of estimates. The first treats twins as individuals (with standard errors taking account of their clustering into twin pairs); the second are the standard, unweighted fixed effect estimates; and the third are fixed effects using IPTW.

The unweighted fixed effect estimates are, in all cases, noticeably lower than those obtained by treating twins as individuals, reflecting the elimination of unobserved heterogeneity between twin pairs. The unweighted fixed effect estimates for SEI are very similar for MZ and DZ twins but rather different for income. Furthermore, for $M Z$ twins, the weighted estimates are slightly greater than the unweighted for SEI and income alike. This is also the case for DZ twins' household income, but the estimate of the effect of education on SEI for them is lower when I weight. Overall, although the magnitude of the differences between fixedeffects estimates appears large in some cases, in none of them is the difference statistically significant at $p<.05$ (based on twin sample interaction term coefficient tests).

\section{Robustness Protocol: Discordance Specification and Influential Twin Pairs}

Table 3 reports estimates using levels, rather than years, of schooling. The treatment weights here come from models predicting discordance in level of education. The unweighted estimates are smaller than the individual estimates among MZ twins and among DZ twins for SEI. For SEI and income alike, weighting the fixed effects usually leads to little noticeable change in the estimated causal effect, and in no cases leads to statistically significant changes.

I undertook further analyses with different specifications of the educational discordance outcome and, additionally, the removal of influential twin pairs as identified by Cook's 
TABLE 2

OLS Estimates of Returns to Education (SEI and Household Income)

\begin{tabular}{|c|c|c|c|c|c|}
\hline \multicolumn{3}{|c|}{ MZ twins } & \multicolumn{3}{|c|}{ DZ twins } \\
\hline \multirow[b]{2}{*}{ Individuals } & \multicolumn{2}{|c|}{ Fixed effects } & \multirow[b]{2}{*}{ Individuals } & \multicolumn{2}{|c|}{ Fixed effects } \\
\hline & Unweighted & Treatment weighted & & Unweighted & Treatment weighted \\
\hline \multicolumn{6}{|c|}{$\mathrm{Y}=$ Socio-economic index (SEI) } \\
\hline $\begin{array}{l}3.740^{* * *} \\
(0.248)\end{array}$ & $\begin{array}{l}3.050^{* * *} \\
(0.721)\end{array}$ & $\begin{array}{l}3.591^{* * *} \\
(0.767)\end{array}$ & $\begin{array}{l}4.087^{* * *} \\
(0.252)\end{array}$ & $\begin{array}{l}3.098^{* * *} \\
(0.825)\end{array}$ & $\begin{array}{l}2.464^{* * *} \\
(0.913)\end{array}$ \\
\hline \multicolumn{6}{|c|}{$Y=$ Annual household income (thousands of U.S. dollars) } \\
\hline $\begin{array}{l}7.562^{* * * *} \\
(1.221)\end{array}$ & $\begin{array}{c}5.471 \\
(4.021)\end{array}$ & $\begin{array}{c}6.265 \\
(4.061)\end{array}$ & $\begin{array}{l}7.926^{* * *} \\
(1.355)\end{array}$ & $\begin{array}{l}7.448^{* *} \\
(3.487)\end{array}$ & $\begin{array}{l}9.747^{* *} \\
(4.250)\end{array}$ \\
\hline
\end{tabular}

Note: Unstandardized OLS estimates are shown for returns to years of education, treating twins as individuals and using twin-pair fixed effects with unweighted and weighted (inverse probability of treatment) data. Standard errors appear in parentheses, below estimates.

${ }^{* * *} p \leq .01 ;{ }^{* *} p \leq .05 ;{ }^{*} p \leq .10$ (two-tailed).

TABLE 3

OLS Estimates of Returns to Education (SEI and Household Income), Levels of Education

\begin{tabular}{|c|c|c|c|c|c|c|}
\hline \multirow[b]{3}{*}{$\begin{array}{l}\text { Level of } \\
\text { education }\end{array}$} & \multicolumn{3}{|c|}{ MZ twins } & \multicolumn{3}{|c|}{ DZ twins } \\
\hline & \multirow[b]{2}{*}{ Individuals } & \multicolumn{2}{|c|}{ Fixed effects } & \multirow[b]{2}{*}{ Individuals } & \multicolumn{2}{|c|}{ Fixed effects } \\
\hline & & Unweighted & $\begin{array}{l}\text { Treatment } \\
\text { weighted }\end{array}$ & & Unweighted & $\begin{array}{l}\text { Treatment } \\
\text { weighted }\end{array}$ \\
\hline & \multicolumn{6}{|c|}{$Y=$ Socio-economic index (SEI) } \\
\hline \multirow{2}{*}{ High school ${ }^{1}$} & $5.048^{* *}$ & 3.536 & 2.440 & $5.649 * * *$ & 0.628 & -0.721 \\
\hline & $(1.803)$ & $(2.176)$ & $(3.227)$ & $(1.391)$ & $(2.535)$ & $(2.597)$ \\
\hline Some college & $\begin{array}{l}10.308^{* * *} \\
(1.865)\end{array}$ & $\begin{array}{l}7.866^{* * * *} \\
(2.279)\end{array}$ & $\begin{array}{l}8.730^{* * * *} \\
(3.494)\end{array}$ & $\begin{array}{l}12.564^{* * *} \\
(1.476)\end{array}$ & $\begin{array}{l}6.152^{* * *} \\
(2.450)\end{array}$ & $\begin{array}{l}5.979^{* *} \\
(2.551)\end{array}$ \\
\hline College & $\begin{array}{l}18.611^{* * *} \\
(2.215)\end{array}$ & $\begin{array}{l}15.684^{* * *} \\
(3.415)\end{array}$ & $\begin{array}{l}16.896^{* * *} \\
(4.296)\end{array}$ & $\begin{array}{l}26.053^{* * *} \\
(1.815)\end{array}$ & $\begin{array}{l}17.633^{* * * *} \\
(3.589)\end{array}$ & $\begin{array}{l}16.126^{* * * *} \\
(3.525)\end{array}$ \\
\hline \multirow[t]{2}{*}{ Graduate } & $\begin{array}{l}30.691 * * * \\
(2.515)\end{array}$ & $\begin{array}{l}24.450^{* * * *} \\
(3.853)\end{array}$ & $\begin{array}{c}23.649^{* * *} \\
(4.639)\end{array}$ & $\begin{array}{c}32.964^{* * *} \\
(2.792) \\
\end{array}$ & $\begin{array}{c}24.194^{* * * *} \\
(3.761)\end{array}$ & $\begin{array}{l}23.094^{* * * *} \\
(3.767) \\
\end{array}$ \\
\hline & \multicolumn{6}{|c|}{$Y=$ Annual household income (thousands of U.S. dollars) } \\
\hline High school $^{1}$ & $\begin{array}{c}4.336 \\
(12.532)\end{array}$ & $\begin{array}{c}-3.081 \\
(14.362)\end{array}$ & $\begin{array}{l}-13.572 \\
(14.014)\end{array}$ & $\begin{array}{c}9.203 \\
(7.691)\end{array}$ & $\begin{array}{c}-6.561 \\
(10.036)\end{array}$ & $\begin{array}{l}-0.146 \\
(8.974)\end{array}$ \\
\hline Some college & $\begin{array}{c}20.110 \\
(13.258)\end{array}$ & $\begin{array}{c}6.288 \\
(15.320)\end{array}$ & $\begin{array}{c}14.643 \\
(14.875)\end{array}$ & $\begin{array}{l}27.321^{* *} \\
(8.761)\end{array}$ & $\begin{array}{c}-2.245 \\
(12.041)\end{array}$ & $\begin{array}{c}1.587 \\
(10.701)\end{array}$ \\
\hline College & $\begin{array}{c}26.895^{*} \\
(13.595)\end{array}$ & $\begin{array}{c}28.296 \\
(19.955)\end{array}$ & $\begin{array}{c}30.451 \\
(18.973)\end{array}$ & $\begin{array}{l}44.556 * * * \\
(10.829)\end{array}$ & $\begin{array}{c}15.651 \\
(16.723)\end{array}$ & $\begin{array}{c}19.401 \\
(17.014)\end{array}$ \\
\hline Graduate & $\begin{array}{l}67.996 * * * \\
(14.900)\end{array}$ & $\begin{array}{c}41.002^{*} \\
(23.108)\end{array}$ & $\begin{array}{c}40.281^{*} \\
(21.863)\end{array}$ & $\begin{array}{l}61.521^{* * *} \\
(14.508)\end{array}$ & $\begin{array}{c}8.223 \\
(18.957)\end{array}$ & $\begin{array}{c}12.400 \\
(17.878)\end{array}$ \\
\hline
\end{tabular}

$d$-statistic. Altogether, these auxiliary results show considerable consistency across all the discordance specifications and estimations of returns to education. They confirm that weighting usually influences estimated returns to education modestly and never yields statistically different estimates from those obtained under no treatment weighting, suggesting that discordance treatment weighting has little effect on overall conclusions about the midlife occupational and financial returns to education, given the life-course factors observed in this study.

\section{Discussion}

Decades of research in the social sciences have argued the importance of identical twins for estimating causal ef- fects of education, yet it has been widely suspected that differences between MZ twins in their education are not random. In this paper, I have sought to establish the degree to which non-random sources of educational variation might bias estimates of midlife returns to education. Using a national sample with detailed information on demographic and childhood backgrounds, I revealed that educational discordance shows some degree of endogeneity to aspects of childhood and adolescent background differing both within and between families. However, when I applied IPTW, using the parameters from models for the propensity of within-pair educational discordance, estimates of the effect of education on annual household income and on occupational SEI were not significantly changed. I conclude, therefore, that educational differences among MZ twins are 
not random and can, to some extent, be explained in terms of measured variables. But, equally, I must also conclude that the outcomes I considered are largely independent of the factors that affect educational differences. Thus, the endogeneity of education within twins does not appear to give rise to bias in causal estimates. Of course, conclusion is necessarily limited to the rich set of predictor variables available in data and leaves open the possibility that there may be unmeasured confounders of the relationship between within-twin educational difference and within-twin outcomes. It is also limited to the specific outcomes I considered because some of the predictors of discordance that I found may also be related to outcomes other than income and SEI. Nevertheless, I believe overall that results should reasonably increase the confidence with which results from analyses of occupation and income using MZ samples are interpreted as unbiased causal estimates.

I carried out the same set of educational analyses for both MZ and DZ twins. Whereas the discordance models for identical twins focus on absolute degree of schooling endogeneity on observables, a replication using same-sex dizygotic twins provided a useful benchmark for evaluating relative endogeneity. In comparing the overall model results across identical and fraternal twins, I surprisingly did not find any solid evidence that schooling among identical twins is substantially closer to resembling a natural experiment. If anything, schooling variation within pairs of identical twins may be slightly more predictable in certain cases, perhaps because differences in childhood and social exposures are rarer among identical twins and thus potentially more important for divergent schooling outcomes.

Numerous studies have calculated the heritability of educational attainment, usually by comparing within-pair schooling concordance of identical and fraternal twins. These studies find higher concordance among identical twins (Branigan et al., 2013). However, these studies do not offer any insight into the nature or predictability of discordance. Following the results here, schooling discordance among identical twins, while rarer than among fraternal twins, may actually be more endogenous to certain childhood exposures.

In drawing on the MIDUS twins, I rely on retrospective accounts of childhood conditions. It should be noted that MIDUS is a uniquely valuable dataset, as identical twin data querying a wide swath of the life course from childhood to midlife remains quite challenging to obtain. While retrospective biases may affect conclusions of traditional cross-sectional analyses of returns to education, their implications for within-pair educational differences remain unclear.

Altogether, this study provides a detailed account of the absolute and relative degree of exogeneity of within-pair schooling differences among identical twins. These results reinforce the earlier anecdotal caveats about the endogeneity of schooling among identical twins. However, the pre- dictors of educational differences between MZ twins do not seem to be important predictors of differences in the adult outcomes I considered and thus do not confound causal estimates derived from the standard MZ twin model.

\section{Acknowledgments}

Thanks to Richard Breen for his statistical guidance and feedback on an earlier draft of this paper. Thanks also to participants in the Yale University Center for Research on Inequalities and the Life Course (CIQLE; now Center for Empirical Research on Stratification and Inequality, CERSI) workshop for their insights and suggestions. This research received no specific grant from any funding agency, commercial or not-for-profit sectors.

\section{Disclosure of Interests}

No known conflicts of interest exist.

\section{Details of Ethical Approval}

The author asserts that all procedures contributing to this work comply with the ethical standards of the relevant national and institutional committees on human experimentation and with the Helsinki Declaration of 1975, as revised in 2008 .

\section{Endnotes}

1 MIDUS twins answered an extensive self-report questionnaire to determine zygosity. The determination is based on a point system, with ambiguous cases left as 'undetermined'. The self-report zygosity method is both typical and seems about 95\% accurate (Lundborg, 2013).

2 Due to a lack of existing theoretical knowledge, I refrain from making specific hypotheses about the directions of associations between educational discordance and within- and between-pair childhood exposures. Competing predictions can be made as to whether exposures will lead twins to resemble each other on educational outcomes or differentiate themselves further through divergent educational trajectories (Bound \& Solon, 1999). Research in econometrics and in social psychology generally suggests that twins may emulate each other more with increased shared exposures (e.g., in the case of peer spillover), but some research also suggests that individuals may oppose or deviate from known expectations for behavior established by a salient significant other such as a co-twin (Amin et al., 2015). Parents, in turn, may try to compensate for emerging differences between identical twins (but see Almond \& Currie, 2011), leading to highly complex interactional dynamics at the family level.

\section{References}

Allison, P. D. (2002). Missing data. Thousand Oaks, CA: Sage.

Almond, D., \& Currie, J. (2011). Human capital development before age five. In D. Card \& O. Ashenfelter ( Eds.), Handbook of labor economics ( vol. 4, Part B, pp. 1315-1486). Oxford: Elsevier. 
Amin, V., Behrman, J. R., Kohler, H.-P., Xiong, Y., \& Zhang, J. (2015). Causal inferences: Identical twins help and clarity about necessary assumptions is critical. Social Science of Medicine, 127, 201-202.

Angrist, J. D., \& Krueger, A. B. (1991). Does compulsory school attendance affect schooling and earnings? Quarterly Journal of Economics, 106, 979-1014.

Astone, N. M., \& McLanahan, S.S. (1991). Family structure, parental practices and high school completion. American Sociological Review, 56, 309-320.

Austin, P. C. (2011). An introduction to propensity score methods for reducing the effects of confounding in observational studies. Multivariate Behavioral Research, 46, 399_ 424.

Behrman, J. R., \& Rosenzweig, M. R. (1999). 'Ability biases' in schooling returns and twins: A test and new estimates. Economics of Education Review, 18, 159-167.

Boardman, J. D., \& Fletcher, J. M. (2015). To cause or not to cause? That is the question, but identical twins might not have all the answers. Social Science and Medicine, 127, 198200.

Bound, J., \& Solon, G. (1999). Double trouble: On the value of twins-based estimation of the return to schooling. Economics of Education Review, 18, 169-182.

Brand, J. E., \& Xie, Y. (2010). Who benefits most from college? Evidence for negative selection in heterogeneous economic returns to higher education. American Sociological Review, 75, 273-302.

Branigan, A. R., McCallum, K. J., \& Freese, J. (2013). Variation in the heritability of educational attainment: An international meta-analysis. Social Forces, 92, 109-140.

Breen, R., Choi, S., \& Holm, A. (2015). Heterogeneous causal effects and sample selection bias. Sociological Science, 2, 351-369.

Card, D. (1999). The causal effect of education on earnings. In D. Card \& O. Ashenfelter ( Eds.), Handbook of labor economics (pp. 1801-1863). Oxford: Elsevier.

Carlin, J. B., Gurrin, L. C., Sterne, J. A. C., Morley, R., \& Dwyer, T. (2005). Regression models for twin studies: A critical review. International Journal of Epidemiology, 34, 1089-1099.

Conti, G., \& Hansman, C. (2013). Personality and the education-health gradient: A note on 'understanding differences in health behaviors by education'. Journal of Health Economics, 32, 480-485.

Conti, G., \& Heckman, J. J. (2010). Early origins of the education-health gradient: A framework that can also be applied to gene-environment interactions. Perspectives on Psychological Science, 5, 585-605.

Crosnoe, R., \& Riegle-Crumb, C. (2007). A life course model of education and alcohol use. Journal of Health and Social Behavior, 48, 267-282.

Entwisle, D. R., Alexander, K. L., \& Olson, L. S. (2005). First grade and educational attainment by age 22: A new story. American Journal of Sociology, 110, 14581502.
Griliches, Z. (1979). Sibling models and data in economics: Beginnings of a survey. Journal of Political Economy, 87, S37S64.

Heckman, J. J., \& Krueger, A. B. (2003). Inequality in America: What role for human capital policies? Cambridge, MA: MIT Press.

Hout, M. (2012). Social and economic returns to college education in the United States. Annual Review of Sociology, 38, 379-400.

Isacsson, G. (1999). Estimates of the return to schooling in Sweden from a large sample of twins. Labour Economics, 6, 471-489.

Kohler, H.-P., Behrman, J. R., \& Schnittker, J. 2011. Social science methods for twins data: Integrating causality, endowments, and heritability. Biodemography and Social Biology, $57,88-141$.

Lundborg, P. (2013). The health returns to schooling - What can I learn from twins? Journal of Population Economics, 26, 673-701.

Lundborg, P., Nilsson, A., \& Rooth, D.-O. (2011). Does early life health predict schooling within twin pairs? IZA Discussion Paper 5803.

Malone, S. M, Luciana, M., Wilson, S., Sparks, J. C., Hunt, R. H., \& Iacono, W. G. (2014). Adolescent drinking and motivated decision-making: A cotwin-control investigation with monozygotic twins. Behavior Genetics, 44, 407418.

McGue, M., Osler, M., \& Christensen, K. (2010). Causal inference and observational research: The utility of twins. Perspectives on Psychological Science, 5, 546-556.

McFarland, M. J., \& Wagner, B.G. (2015). Does a college education reduce depressive symptoms in American young adults? Social Science \& Medicine, 146, 75-84.

McFarland, M. J., Wagner, B. G., \& Marklin, S. (2016). College education and sense of control: A twin-discordant design. Socius: Sociological Research for a Dynamic World, 2, 1-12.

McLeod, J. D., \& Fettes, D. L. (2007). Trajectories of failure: The educational careers of children with mental health problems. American Journal of Sociology, 113, 653-701.

Pischke, J.-S., \& von Wachter, T. (2008). Zero returns to compulsory schooling in Germany: Evidence and interpretation. Review of Economics and Statistics, 90, 592-598.

Pribesh, S., \& Downey, D. B. (1999). Why are residential and school moves associated with poor school performance? Demography, 36, 521-534.

Sandewall, Ö., Cesarini, D., \& Johannesson, M. (2014). The cotwin methodology and returns to schooling-Testing a critical assumption. Labour Economics, 26, 1-10.

Sewell, W. H., Haller, A. O., \& Portes, A. (1969). The educational and early occupational attainment process. American Sociological Review, 34, 82-92.

South, S. J., \& Haynie, D. L. (2004). Friendship networks of mobile adolescents. Social Forces, 83, 315-350.

von Hippel, P. T., \& Lynch, J. L. (2014). Why are educated adults slim - Causation or selection? Social Science and Medicine, 105, 131-139. 


\section{Appendix A Descriptive Statistics for MIDUS Twins Samples}

TABLE A.1

Descriptive Statistics, 1995 MIDUS Twins

\begin{tabular}{|c|c|c|c|c|}
\hline \multirow[b]{2}{*}{ Variable } & \multicolumn{2}{|c|}{ MZ } & \multicolumn{2}{|c|}{ Same-sex DZ } \\
\hline & M & $S D$ & M & $S D$ \\
\hline \multicolumn{5}{|l|}{ Educational variables and outcomes } \\
\hline Occupational SEI & 38.42 & 14.12 & 37.64 & 15.15 \\
\hline Household income & 75461.78 & 59937.06 & 71948.53 & 62153.80 \\
\hline Education (years) & 13.94 & 2.31 & 13.42 & 2.59 \\
\hline $\begin{array}{l}\text { Pair difference in occupation } \\
\text { (SEI) }\end{array}$ & 10.98 & 9.50 & 12.52 & 10.78 \\
\hline Pair difference in $\mathrm{HH}$ income & 49102.99 & 51957.17 & 52306.12 & 51872.54 \\
\hline $\begin{array}{l}\text { Pair difference in education } \\
\text { (years) }\end{array}$ & 1.15 & 1.47 & 1.61 & 1.79 \\
\hline \multicolumn{5}{|l|}{ Discordance equation variables } \\
\hline Male & 0.47 & 0.50 & 0.38 & 0.49 \\
\hline Age & 43.99 & 11.90 & 45.48 & 12.22 \\
\hline White & 0.94 & 0.23 & 0.94 & 0.25 \\
\hline $\begin{array}{l}\text { Parent education: HS or some } \\
\text { college }\end{array}$ & 0.54 & 0.50 & 0.51 & 0.50 \\
\hline Parent education: college+ & 0.21 & 0.41 & 0.19 & 0.39 \\
\hline $\begin{array}{l}\text { Parent SEl: moderate (second } \\
\text { 25\%) }\end{array}$ & 0.25 & 0.43 & 0.25 & 0.43 \\
\hline Parent SEI: high (top half) & 0.49 & 0.50 & 0.50 & 0.50 \\
\hline Moves during childhood & 1.40 & 1.49 & 1.39 & 1.55 \\
\hline $\begin{array}{l}\text { Welfare receipt during } \\
\text { childhood }\end{array}$ & 0.07 & 0.25 & 0.09 & 0.28 \\
\hline $\begin{array}{l}\text { Grew up in rural/small town } \\
\text { setting }\end{array}$ & 0.51 & 0.50 & 0.55 & 0.50 \\
\hline Parental health status & 3.49 & 0.95 & 3.31 & 0.96 \\
\hline $\begin{array}{l}\text { Same bedroom (for 16-18 } \\
\text { years) }\end{array}$ & 0.74 & 0.44 & 0.72 & 0.45 \\
\hline$<18$ years living together & 0.17 & 0.38 & 0.26 & 0.44 \\
\hline $\begin{array}{l}\text { Same playmates always/most } \\
\text { of time }\end{array}$ & 0.89 & 0.31 & 0.74 & 0.44 \\
\hline $\begin{array}{l}\text { Same classrooms always/most } \\
\text { of time }\end{array}$ & 0.59 & 0.49 & 0.47 & 0.50 \\
\hline Same weight during childhood & 0.91 & 0.29 & 0.60 & 0.49 \\
\hline $\begin{array}{l}\text { Distant relatives couldn't tell } \\
\text { apart }\end{array}$ & 0.72 & 0.45 & 0.12 & 0.32 \\
\hline $\begin{array}{l}\text { Acquaintances couldn't tell } \\
\text { apart }\end{array}$ & 0.68 & 0.47 & 0.10 & 0.29 \\
\hline Difference in birth weight (lbs) & 0.33 & 0.55 & 0.28 & 0.57 \\
\hline Difference in parent discipline & 0.46 & 0.45 & 0.54 & 0.52 \\
\hline Difference in early drinking & 0.10 & 0.29 & 0.13 & 0.33 \\
\hline Difference in early smoking & 0.16 & 0.37 & 0.24 & 0.43 \\
\hline $\begin{array}{l}\text { Difference in early mental } \\
\text { health }\end{array}$ & 0.18 & 0.38 & 0.23 & 0.42 \\
\hline
\end{tabular}

\section{Appendix B Discordance Model Results for MIDUS Twins Samples}

\section{TABLE B.1}

FIML Estimates, Educational Discordance Models, MZ Twins

\begin{tabular}{|c|c|c|c|c|}
\hline & \multicolumn{2}{|c|}{$\begin{array}{l}\text { Discordance } \\
=1 \text { year }\end{array}$} & \multicolumn{2}{|c|}{$\begin{array}{l}\text { Discordance } \\
=2 \text { years }\end{array}$} \\
\hline & $b$ & $S E(b)$ & $b$ & $S E(b)$ \\
\hline Male & 0.025 & 0.044 & 0.022 & 0.048 \\
\hline Age: $25-34$ & -0.023 & 0.081 & -0.046 & 0.089 \\
\hline Age: $35-40$ & 0.040 & 0.087 & 0.009 & 0.090 \\
\hline Age: $45-50$ & -0.081 & 0.086 & -0.051 & 0.090 \\
\hline Age: 51-60 & -0.107 & 0.092 & 0.074 & 0.109 \\
\hline Age: $60+$ & -0.064 & 0.098 & -0.097 & 0.103 \\
\hline White & 0.095 & 0.077 & $0.187^{* *}$ & 0.085 \\
\hline Parent education: HS/some college & 0.024 & 0.053 & $0.124^{* *}$ & 0.055 \\
\hline Parent education: college + & -0.090 & 0.071 & $0.198^{* * *}$ & 0.075 \\
\hline Parental SEI: moderate & -0.035 & 0.067 & -0.020 & 0.069 \\
\hline Parental SEI: high & -0.049 & 0.065 & -0.069 & 0.064 \\
\hline Moved once & 0.060 & 0.057 & 0.014 & 0.068 \\
\hline Moved twice & 0.113 & 0.082 & -0.090 & 0.087 \\
\hline Moved three times & 0.113 & 0.077 & $-0.147^{*}$ & 0.088 \\
\hline Moved four+ times & 0.117 & 0.074 & -0.015 & 0.077 \\
\hline Welfare receipt & 0.062 & 0.101 & -0.010 & 0.083 \\
\hline Rural/small town & 0.037 & 0.048 & -0.045 & 0.060 \\
\hline Parental health & 0.016 & 0.021 & -0.034 & 0.025 \\
\hline $16+$ years in the same bedroom & -0.028 & 0.050 & $0.124^{* *}$ & 0.058 \\
\hline$<18$ years living together & -0.043 & 0.054 & 0.080 & 0.069 \\
\hline Same playmates & $-0.162^{*}$ & 0.090 & 0.073 & 0.097 \\
\hline Same classrooms & 0.049 & 0.051 & $-0.141^{* * *}$ & 0.058 \\
\hline Different weight & 0.085 & 0.063 & 0.005 & 0.083 \\
\hline Relatives confused & -0.033 & 0.049 & $0.143^{* * *}$ & 0.051 \\
\hline Acquaintances confused & -0.063 & 0.048 & $-0.103^{* *}$ & 0.053 \\
\hline Difference in birth weight & -0.049 & 0.040 & 0.029 & 0.070 \\
\hline Difference in parental discipline & -0.070 & 0.050 & -0.049 & 0.059 \\
\hline Difference in early drinking & 0.103 & 0.083 & $-0.156^{* *}$ & 0.073 \\
\hline Difference in early smoking & 0.046 & 0.059 & -0.023 & 0.064 \\
\hline Difference in early mental health & 0.015 & 0.057 & 0.069 & 0.066 \\
\hline Constant & 0.169 & 0.185 & 0.055 & 0.213 \\
\hline
\end{tabular}

Note: $\quad N=310$ identical (MZ) twin pairs. Unstandardized FIML estimates are shown for two separate linear probability models, predicting 1 year of within-pair discordance (vs. 0 or 2 years) and 2 years of discordance (vs. 0 or 1 year). Standard errors are robust.

${ }^{* * *} p \leq .01 ; * * p \leq .05 ;{ }^{*} p \leq .10$ (two-tailed) 


\section{TABLE B.2}

FIML Estimates, Educational Discordance Models, Same-Sex DZ Twins

\begin{tabular}{|c|c|c|c|c|}
\hline & \multicolumn{2}{|c|}{$\begin{array}{l}\text { Discordance } \\
=1 \text { year }\end{array}$} & \multicolumn{2}{|c|}{$\begin{array}{l}\text { Discordance } \\
=2 \text { years }\end{array}$} \\
\hline & $b$ & $S E(b)$ & $b$ & $S E(b)$ \\
\hline Male & 0.032 & 0.043 & -0.061 & 0.068 \\
\hline Age: 25-34 & $0.152^{* *}$ & 0.074 & 0.188 & 0.137 \\
\hline Age: $35-40$ & $0.127^{* *}$ & 0.067 & 0.064 & 0.136 \\
\hline Age: $45-50$ & $0.147^{*}$ & 0.081 & 0.015 & 0.130 \\
\hline Age: $51-60$ & 0.033 & 0.076 & 0.106 & 0.140 \\
\hline Age: $60+$ & 0.038 & 0.075 & 0.130 & 0.141 \\
\hline White & -0.015 & 0.091 & -0.034 & 0.116 \\
\hline Parent education: HS/some college & -0.024 & 0.058 & -0.079 & 0.078 \\
\hline Parent education: college+ & 0.052 & 0.088 & 0.024 & 0.115 \\
\hline Parental SEI: moderate & 0.059 & 0.073 & 0.157 & 0.098 \\
\hline Parental SEl: high & -0.045 & 0.068 & $0.206^{* *}$ & 0.095 \\
\hline Moved once & 0.013 & 0.062 & 0.015 & 0.093 \\
\hline Moved twice & 0.128 & 0.095 & 0.028 & 0.103 \\
\hline Moved three times & 0.005 & 0.079 & 0.030 & 0.144 \\
\hline Moved four+ times & $0.144^{* *}$ & 0.073 & $0.161^{*}$ & 0.090 \\
\hline Welfare receipt & -0.033 & 0.096 & 0.088 & 0.110 \\
\hline Rural/small town & 0.003 & 0.056 & 0.001 & 0.077 \\
\hline Parental health & -0.007 & 0.023 & $-0.067^{* *}$ & 0.035 \\
\hline $16+$ years in the same bedroom & 0.019 & 0.047 & -0.056 & 0.071 \\
\hline$<18$ years living together & 0.080 & 0.060 & -0.059 & 0.075 \\
\hline Same playmates & 0.050 & 0.043 & $-0.155^{* *}$ & 0.073 \\
\hline Same classrooms & -0.048 & 0.048 & 0.056 & 0.067 \\
\hline Different weight & -0.040 & 0.042 & -0.041 & 0.063 \\
\hline Relatives confused & -0.056 & 0.076 & -0.167 & 0.121 \\
\hline Acquaintances confused & -0.025 & 0.067 & 0.022 & 0.117 \\
\hline Difference in birth weight & 0.021 & 0.082 & $-0.174^{* * *}$ & 0.066 \\
\hline Difference in parental discipline & -0.042 & 0.039 & -0.078 & 0.065 \\
\hline Difference in early drinking & $-0.170^{* * *}$ & 0.051 & 0.077 & 0.087 \\
\hline Difference in early smoking & 0.020 & 0.053 & 0.060 & 0.071 \\
\hline Difference in early mental health & -0.062 & 0.042 & 0.072 & 0.074 \\
\hline Constant & 0.048 & 0.191 & $0.596^{* *}$ & 0.263 \\
\hline
\end{tabular}

Note: $N=242$ same-sex fraternal (DZ) twin pairs. Unstandardized FIML estimates are shown for two separate linear probability models, predicting 1 year of within-pair discordance (vs. 0 or 2 years) and 2 years of discordance (vs. 0 or 1 year). Standard errors are robust.

${ }^{* * *} p \leq .01 ;{ }^{* *} p \leq .05 ;{ }^{*} p \leq .10$ (two-tailed).
TABLE B.3

FIML Estimates, Educational Discordance Models, MZ Twins

\begin{tabular}{|c|c|c|c|c|}
\hline & \multicolumn{2}{|c|}{$\begin{array}{l}\text { Discordance } \\
=1 \text { level }\end{array}$} & \multicolumn{2}{|c|}{$\begin{array}{l}\text { Discordance } \\
=2 \text { levels }\end{array}$} \\
\hline & $b$ & $S E(b)$ & $b$ & SE (b) \\
\hline Male & 0.076 & 0.050 & 0.013 & 0.027 \\
\hline Age: $25-34$ & -0.048 & 0.094 & 0.018 & 0.038 \\
\hline Age: $35-40$ & 0.052 & 0.096 & 0.010 & 0.033 \\
\hline Age: $45-50$ & -0.076 & 0.097 & 0.047 & 0.040 \\
\hline Age: $51-60$ & -0.114 & 0.095 & $0.157^{* * *}$ & 0.060 \\
\hline Age: $60+$ & -0.036 & 0.109 & $0.098^{*}$ & 0.057 \\
\hline White & $0.186^{* *}$ & 0.092 & -0.084 & 0.078 \\
\hline Parent education: HS/some college & 0.090 & 0.061 & 0.053 & 0.033 \\
\hline Parent education: college + & 0.029 & 0.087 & -0.024 & 0.043 \\
\hline Parental SEI: moderate & $-0.155^{* *}$ & 0.075 & 0.002 & 0.038 \\
\hline Parental SEl: high & -0.071 & 0.070 & 0.035 & 0.041 \\
\hline Moved once & 0.051 & 0.068 & 0.000 & 0.037 \\
\hline Moved twice & -0.018 & 0.087 & 0.018 & 0.053 \\
\hline Moved three times & 0.010 & 0.101 & 0.027 & 0.057 \\
\hline Moved four + times & 0.073 & 0.083 & -0.034 & 0.040 \\
\hline Welfare receipt & -0.037 & 0.113 & -0.023 & 0.053 \\
\hline Rural/small town & 0.005 & 0.058 & 0.002 & 0.029 \\
\hline Parental health & -0.027 & 0.027 & -0.005 & 0.014 \\
\hline $16+$ years in same bedroom & $0.102^{*}$ & 0.059 & 0.009 & 0.027 \\
\hline$<18$ years living together & 0.112 & 0.072 & 0.065 & 0.041 \\
\hline Same playmates & -0.110 & 0.091 & -0.046 & 0.056 \\
\hline Same classrooms & -0.094 & 0.060 & -0.039 & 0.031 \\
\hline Different weight & $0.151^{*}$ & 0.085 & 0.017 & 0.032 \\
\hline Relatives confused & $0.105^{*}$ & 0.055 & $0.063^{* *}$ & 0.028 \\
\hline Acquaintances confused & $-0.142^{* * *}$ & 0.058 & 0.032 & 0.025 \\
\hline Difference in birth weight & 0.014 & 0.075 & -0.009 & 0.020 \\
\hline Difference in parental discipline & $-0.128^{* *}$ & 0.062 & -0.031 & 0.032 \\
\hline Difference in early drinking & 0.069 & 0.092 & 0.044 & 0.051 \\
\hline Difference in early smoking & $0.125^{*}$ & 0.070 & -0.035 & 0.028 \\
\hline Difference in early mental health & 0.082 & 0.065 & 0.042 & 0.038 \\
\hline Constant & 0.206 & 0.209 & 0.040 & 0.136 \\
\hline
\end{tabular}

Note: $N=343$ identical (MZ) twin pairs. Unstandardized FIML estimates are shown for two separate linear probability models, predicting 1 level of within-pair educational discordance (vs. 0 or 2 levels) and 2 levels of discordance (vs. 0 or 1 levels). Standard errors are robust. ${ }^{* * *} p \leq .01 ;{ }^{* *} p \leq .05 ; * p \leq .10$ (two-tailed). 
TABLE B.4

FIML Estimates, Educational Discordance Models, Same-Sex DZ Twins

\begin{tabular}{|c|c|c|c|c|}
\hline & \multicolumn{2}{|c|}{$\begin{array}{l}\text { Discordance } \\
=1 \text { level }\end{array}$} & \multicolumn{2}{|c|}{$\begin{array}{l}\text { Discordance } \\
=2 \text { levels }\end{array}$} \\
\hline & b & $S E(b)$ & b & $S E(b)$ \\
\hline Male & 0.039 & 0.061 & -0.007 & 0.044 \\
\hline Age: $25-34$ & $0.278^{* * *}$ & 0.114 & -0.029 & 0.083 \\
\hline Age: $35-40$ & $0.281^{* *}$ & 0.117 & -0.063 & 0.082 \\
\hline Age: $45-50$ & 0.160 & 0.115 & -0.093 & 0.081 \\
\hline Age: $51-60$ & 0.161 & 0.120 & -0.035 & 0.086 \\
\hline Age: $60+$ & 0.104 & 0.121 & -0.031 & 0.094 \\
\hline White & 0.050 & 0.117 & $0.115^{* *}$ & 0.050 \\
\hline Parent education: $\mathrm{HS} /$ some college & -0.044 & 0.075 & 0.044 & 0.048 \\
\hline Parent & 0.106 & 0.113 & -0.067 & 0.079 \\
\hline Parental SEI: moderate & 0.108 & 0.088 & -0.058 & 0.063 \\
\hline Parental SEl: high & 0.094 & 0.085 & 0.088 & 0.064 \\
\hline Moved once & -0.064 & 0.091 & -0.020 & 0.055 \\
\hline Moved & 0.034 & 0.098 & 0.133 & 0.082 \\
\hline Moved three times & 0.058 & 0.134 & -0.080 & 0.051 \\
\hline Movec & $0.200^{* *}$ & 0.086 & 0.004 & 0.063 \\
\hline Welfare receipt & 0.073 & 0.105 & -0.046 & 0.064 \\
\hline & 0.002 & 0.071 & 0.001 & 0.04 \\
\hline Parental health & -0.041 & 0.032 & 0.016 & 0.02 \\
\hline $16+$ years in same & 0.006 & 0.065 & 0.032 & 0.043 \\
\hline$<18$ yea & 0.047 & 0.072 & -0.051 & 0.047 \\
\hline Same playmates & -0.082 & 0.066 & 0.048 & 0.043 \\
\hline & & 0.065 & & 0.042 \\
\hline & -0.029 & 0.059 & -0.018 & 0.0 \\
\hline Relatives confused & -0.131 & 0.099 & 0.079 & 0.075 \\
\hline Acquaintances confused & 0.008 & 0.113 & -0.022 & 0.066 \\
\hline Difference in birth w & -0.115 & 0.080 & -0.045 & 0.0 \\
\hline Difference in parental discipline & -0.006 & 0.060 & -0.008 & 0.039 \\
\hline Difference in early drinking & $-0.150^{*}$ & 0.082 & 0.025 & \\
\hline Difference in early smoking & 0.012 & 0.070 & 0.026 & 0.0 \\
\hline Difference in early mental health & -0.003 & 0.070 & -0.061 & \\
\hline Constant & 0.274 & 0.236 & -0.057 & 0.16 \\
\hline
\end{tabular}

Note: $N=294$ same-sex fraternal (DZ) twin pairs. Unstandardized FIML estimates are shown for two separate linear probability models, predicting 1 level of within-pair educational discordance (vs. 0 or 2 levels) and 2 levels of discordance (vs. 0 or 1 levels). Standard errors are robust. ${ }^{* * *} p \leq .01 ; * * p \leq .05 ;{ }^{*} p \leq .10$ (two-tailed).

\section{Appendix C Descriptive Statistics for Discordance Treatment Weights}

\section{TABLE C.1}

Distributions of Stabilized Inverse Probability of Treatment (IPT) Weights, MZ and DZ Twins

\begin{tabular}{|c|c|c|c|c|}
\hline \multirow[b]{2}{*}{ Discordance procedure } & \multicolumn{2}{|c|}{ MZ twins } & \multicolumn{2}{|c|}{ DZ twins } \\
\hline & Years & Levels & Years & Levels \\
\hline Mean & 1.057 & 1.042 & 0.968 & 0.993 \\
\hline $\begin{array}{l}\text { Standard deviation } \\
\text { Percentiles }\end{array}$ & 1.679 & 1.243 & 0.459 & 0.472 \\
\hline $1 \%$ & 0.483 & 0.453 & 0.458 & 0.503 \\
\hline $5 \%$ & 0.592 & 0.568 & 0.528 & 0.597 \\
\hline $10 \%$ & 0.637 & 0.620 & 0.589 & 0.657 \\
\hline $25 \%$ & 0.743 & 0.718 & 0.705 & 0.750 \\
\hline $50 \%$ & 0.886 & 0.849 & 0.873 & 0.882 \\
\hline $75 \%$ & 1.119 & 1.088 & 1.082 & 1.068 \\
\hline $90 \%$ & 1.393 & 1.515 & 1.401 & 1.410 \\
\hline $95 \%$ & 1.622 & 1.758 & 1.793 & 1.784 \\
\hline $99 \%$ & 1.995 & 3.509 & 2.764 & 3.729 \\
\hline \multicolumn{5}{|c|}{$\begin{array}{l}\text { Note: Weights are determined by discordance propensities and actual (ob- } \\
\text { served) discordance. Weights are stabilized by multiplying by the pro- } \\
\text { portion of pairs showing any discordance. }\end{array}$} \\
\hline
\end{tabular}

